\title{
Retrospective analysis of impacted first and second permanent molars in the Turkish population: A multicenter study
}

\author{
Cihan Bereket ${ }^{1}$, Nilüfer Çakır-Özkan ${ }^{1}$, İsmail Şener ${ }^{1}$, İsa Kara ${ }^{2}$, Ali-Murat Aktan ${ }^{3}$, Nursel Arıcı ${ }^{4}$
}

${ }^{1}$ DDS, PhD. Assistant Professor, Department of Oral and Maxillofacial Surgery, Faculty of Dentistry, Ondokuz Mayis University, Samsun, Turkey

${ }^{2}$ DDS, PhD. Assistant Professor, Department of Oral and Maxillofacial Surgery, Faculty of Dentistry, Gaziantep University, Gaziantep, Turkey

${ }^{3}$ DDS, PhD. Assistant Professor, Department of Oral Diagnosis and Radiology, Faculty of Dentistry, Gaziantep University, Gaziantep, Turkey

${ }^{4}$ DDS, PhD. Assistant Professor, Department of Orthodontics, Faculty of Dentistry, Ondokuz Mayis University, Samsun, Turkey

Correspondence:

Ondokuz Mayls Üniversitesi,

Diș Hekimliği Fakültesi.

Samsun, Turkey

isener@hotmail.com

Received: $11 / 05 / 2010$

Accepted: 14/11/2010
Bereket C, Cakir-Özkan N, Sener I, Kara I, Aktan AM, Arici N. Re-trospective analysis of impacted first and second permanent molars in the Turkish population: A multicenter study. Med Oral Patol Oral Cir Bucal. 2011 Nov 1;16 (7):e874-8.

http://www.medicinaoral.com/medoralfree01/v16i7/medoralv16i7p874.pdf

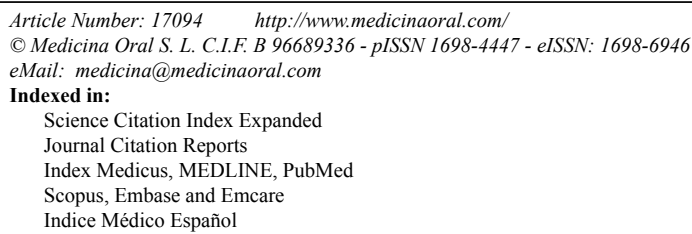

Science Citation Index Expanded

Journal Citation Reports

Index Medicus, MEDLINE, PubMed

Scopus, Embase and Emcare

Indice Médico Españo

\begin{abstract}
Objectives: The purpose of the present study was to retrospectively analyze 170 case series of patients with 200 impacted first and second permanent molars.

Study Design: Records of 104.408 patients were retrospectively screened in this multicenter study. The chosen study population consists of 170 patients who presented with impacted or retained first and second permanent molar. All patients with impacted first or second permanent molar had undergone clinical and radiographic examinations. The following factors were analyzed: age and gender, frequency, distribution, location, position, the number of impacted tooth, primary and secondary retention, degree of infraocclusion, associated pathologic conditions and treatment method.

Results: There were a total of 170 patients (male: 91 , female: 79 , mean ages $22.69 \pm 8.99$ years ranging from 13 to 66 years of age) with 200 retained or impacted permanent molars in 104.408 patients. In this study, 200 impacted teeth which were analyzed were 125 molars $(62.5 \%)$ vertical position, $17(8.5 \%)$ horizontal, $38(19 \%)$ mesioangular, $12(6 \%)$ distoangular, and $7(3.5 \%)$ buccolingual inclination. There were 52 primarily retained (26\%) and 32 secondarily retained (16\%) molars. 137 (68.5\%) molars were asymptomatic. Cystic formation was present in 13 $(6.5 \%)$ cases.

Conclusions: Although the impactions of first and second permanent molars do not occur frequently, it is important to make an early diagnosis in order to start treatment at the optimal time.
\end{abstract}

Key words: Impacted first molar, impacted second molar. 


\section{Introduction}

The impaction of permanent teeth usually concerns the third molars, maxillary canines or central incisors, and mandibular second premolars (1). The impaction of permanent first and second molars is uncommon, with prevalence rates of $0.08 \%$ for the second maxillary molar and less than $0.01 \%$ for the first mandibular molar (2).

Impacted teeth are those prevented from erupting by some physical barrier in the eruption path. If eruption has been arrested but neither a physical barrier nor an abnormal position eruption path is present, then the tooth is said to be primarily retained. Secondary retention refers to the cessation of tooth eruption after emergence, where the cause is neither a physical barrier in the path of eruption nor abnormal positioning. The etiology of impaction is related to several local and systemic factors (3). Some of these factors are: presence of a supernumerary tooth, odontogenic and non-odontogenic lesions, deficient arch length, premature loss of primary teeth, or retained primary teeth. Some systemic factors involved include conditions such as cleidocranial dysostosis, Down's syndrome, hypothyroidism, and hypopituitarism (4).

Based on Winter's classification systems, impacted molars can be classified as vertical, distoangular, mesioangular, or horizontal in position according to tooth angulation. The occlusal plane can be used as a reference to check the depth of the impacted molars (3).

Treatment of impaction of a permanent molar consists of surgical exposure, extraction, and removal of any possible barrier $(5,6)$. Orthodontic treatment should follow in the event of abnormal positioning of the tooth, malocclusion, lack of space in the dental arch, or if spontaneous eruption is not expected (2).

Due to the low prevalence of impaction of the first and second permanent molars, there is a lack of uniformity in the management of these impacted teeth, and published reports are mostly based on case reports and mesially inclined molars. The purpose of the present study was to retrospectively analyze 170 case series of patients with 200 impacted first and second permanent molars.

\section{Materials and Methods}

Records of 104.408 patients from four cities in the different regions of Turkey were retrospectively screened in this multicenter study. The study population consists of 170 patients who presented with impacted or retained first and second molars. For all patients in the sample, the annual records and panoramic radiographs, in some instances supplemented by periapical and occlusal radiographs, were examined. The analysis of the radiographs was carried out by a dental radiologist under standard conditions. In a second step, all radiographs were reexamined by another examiner. The following factors were recorded: age and gender, frequency, distri- bution, location, the number of impacted teeth, primary and secondary retention, position, degree of infraocclusion, associated pathologic conditions, and treatment method. The degree of infraocclusion was considered mild, moderate and severe, as defined by Brearley and McKibben (7).

The chi-squared test was performed to determine the statistical significance of differences in prevalence of findings between the sexes, between upper and lower jaws, and between the right and left sides of the patient. Differences with probabilities of less than $(p<.05)$ were considered statistically significant.

\section{Results}

The overall prevalence of the impacted teeth in 104.408 patients was shown in (Table 1). There were a total of 170 patients (male: 91 , female: 79 ; mean ages $22.69 \pm 8.99$ years ranging from 13 to 66 years of age) with retained or impacted first and second permanent molars in 104.408 patients. A total of 200 retained or impacted permanent molars were found in 170 patients (Fig. 1). Impaction of

Table 1. The overall prevalence of the impacted teeth in 104408 patients.

\begin{tabular}{|c|c|c|}
\hline & Number & Percentage (\%) \\
\hline Second Molar & 168 & 0,16 \\
\hline Upper & 81 & 0,08 \\
\hline Lower & 87 & 0,07 \\
\hline First Molar & 32 & 0,03 \\
\hline Upper & 17 & 0,01 \\
\hline Lower & 15 & 0,01 \\
\hline Total & 200 & 0.19 \\
\hline
\end{tabular}

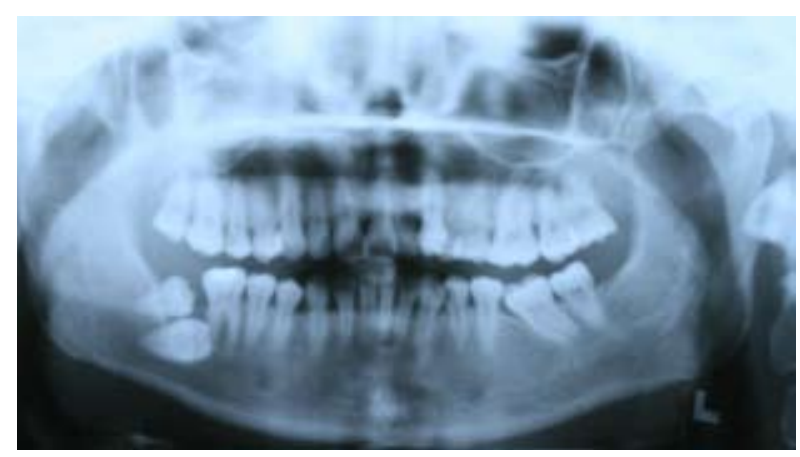

Fig. 1. Panoramic radiograph showing right mandibular impacted second molar. 
more than one permanent molar (excluding third molars) was present in 28 patients (14\%) (Fig. 2). In this study, the 200 impacted teeth which were analyzed included 125 molars $(62.5 \%)$ in vertical position, 17 (8.5\%) horizontal, 38 (19\%) mesioangular, 12 (6\%) distoangular, and 7 (3.5\%) of buccolingual inclination (Table 2). The degree of tooth infraocclusion was considered mild in $22(11 \%)$ cases, moderate in $94(47 \%)$ cases, and severe in $84(42 \%)$ cases (Table 3$)$. It was considered to be primarily retained in $52(26 \%)$ molars and secondarily retained in 32 (16\%) molars. 137 (68.5\%) molars were asymptomatic. In 21 molars (10.5\%), a history of pericoronitis and/or extensive caries was present, and 10 molars had root development abnormalities. Cystic lesion associated the impacted teeth was present in 13 $(6.5 \%)$ cases. In $29(14.5 \%)$ cases, there was adjacent tooth pathology such as caries or root resorption (Table 4).

There was no statistically significant difference between the sexes or between the jaws. The prevalence of impacted molars was found to be highest in the right maxillary region of females $(\mathrm{p}=0.006)$.

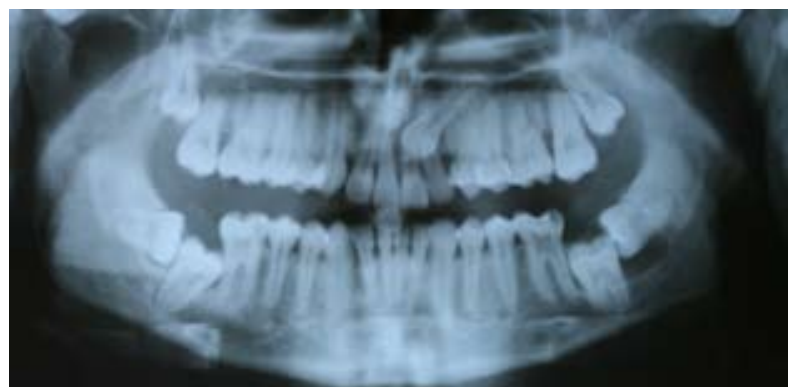

Fig. 2. Panoramic radiograph showing bilaterally impacted second molars.
Table 3. The infraocclusion degree of the impacted teeth.

\begin{tabular}{|c|c|c|}
\hline Infraocclusion degree & Number & Percentage (\%) \\
\hline Mild & 22 & 11 \\
\hline Moderate & 94 & 47 \\
\hline Severe & 84 & 42 \\
\hline Total & 200 & 100 \\
\hline
\end{tabular}

Table 4. Complications caused by impacted teeth.

\begin{tabular}{|c|c|c|}
\hline Complication & Number & Percentage (\%) \\
\hline Pathology (cyst) & 13 & 6.5 \\
\hline Infection (pericoronitis, abscess) & 21 & 10.5 \\
\hline Adjacent tooth pathology & 29 & 14.5 \\
\hline Asymptomatic & 137 & 68.5 \\
\hline Total & 200 & 100 \\
\hline
\end{tabular}

According to the patient records, 119 molars were surgically extracted, 47 molars were orthodontically treated, and the remaining 30 molars were not treated because they were symptomless and their prognosis was poor.

\section{Discussion}

The prevalence of impaction of permanent molars is low. The incidence of second molar impaction revealed by panoramic radiograph studies has been reported as 0.03-0.04\%. Grover and Lorton surveyed 5,000 panoramic radiographs of Army recruits and reported that the most frequently non-erupted permanent molars were the second molars $(0.08 \%$ of the population for upper second molars and $0.06 \%$ for lower second molars) (8). Impacted maxillary first molars were found in $0.02 \%$ of the population (9). Dachi and Howell reported only three impacted mandibular first molars in their 1,218 patients with impactions (10). Our results are in accordance with the literature. The incidence of second molar impaction is estimated by Varpio and Welfelt to be $0.7 \%$ (11). In this study, we found the prevalence of impacted or retained second molar to be $0.16 \%(0.07 \%$ lower, $0.08 \%$ upper), and of first molar to be $0.03 \%$ ( $0.01 \%$ lower, $0.01 \%$ upper).

With regard to the impacted molars, there was a signifi- 
cantly higher incidence in males and a higher incidence on the right side. In this series, the male to female ratio was 1.15:1 and there was a higher incidence in the right maxillary region, in agreement with previous studies. It has been reported that second molar impactions occur more frequently in the mandible $(11,12)$. This is contrary to our findings, as we found that impacted first and second molars occurred more frequently in the maxilla.

In this study, with regard to the axis of the tooth we found non-erupted molars were infraoccluded in a 125 $(62.5 \%)$ vertical position, 17 (8.5\%) were horizontal, 38 $(19 \%)$ were mesioangular, and $12(6 \%)$ were distoangular; this is in line with report by Castellon et al. (2), who found $22(53 \%)$ non-erupted molars were infraoccluded in a vertical position, $5(12 \%)$ were horizontal, $8(19 \%)$ were distoangular, and $7(16 \%)$ had a mesioangular inclination in their 43 case series. In contrast, Castellon et al. (2) found that the infraocclusion was severe in most cases, while we found the degree of tooth infraocclusion was moderate in most cases $(47 \%)$. This may have resulted from the sample size and racial differences between the two series.

Generally, impaction of permanent molars occurs in asymptomatic patients and is not noticed by the patient. In most cases, it is not the impacted first or second molar that is the reason for the referral. Thus, the discovery of an impaction usually occurs during a routine visit and this leads to a late diagnosis (13). Most of our cases $(68.5 \%)$ were asymptomatic and were noticed during routine radiographic examination.

The clinical complications of impacted molars include infection, cyst formation, and resorption of adjacent teeth. Cyst formation was present in $13(6.5 \%)$ cases, and $21(10.5 \%)$ molars had a history of pericoronitis. In $29(14.5 \%)$ cases, there was neighboring tooth pathology such as caries or root resorption. Because the published studies were mostly based on single case reports, we could not compare our results with the literature. Castellon et al. (2) reported that a follicular cyst was present in $8(19 \%)$ cases in their series, while we observed cyst formation in 13 cases $(16.5 \%)$.

The etiological factors responsible for tooth impactions may be divided in two main groups. Local factors include an increase in bone deposition, trauma, malposition, prolonged retention of primary teeth, and local pathosis. Systemic factors consist of conditions such as childhood diseases, hereditary factors, cleft palate and cleidocranial dysostosis (8). During the tooth eruption, bone resorption occurs ahead of the moving tooth and bone is deposited apically (14). The change in direction of root formation and the possibility of a developing ankylosis may further reduce the tooth's eruptive potential. We considered arrested eruption due to the presence of a physical barrier or an abnormal eruption path in 116 (58\%) impacted molars. The remaining 52 (26\%) molars were primarily retained, and $32(16 \%)$ molars were secondarily retained. Bondemark and Tsiopa (15) found that the prevalence of primary retention and impaction were $0.6 \%$ and $0.2 \%$, respectively, in 1,543 patients. We found that the prevalence of primary retention and impaction were $0.04 \%$ and $0.11 \%$, respectively, in 104.408 patients. The difference may have resulted from the sample size, age, and racial differences between the two series.

The treatment of impacted teeth depends on many factors. Thus, there can be confusion in the management of an impacted tooth when deciding whether they should be surgically removed, orthodontically treated, or simply followed up regularly.

Orthodontics is a major modality in the treatment of impacted and primarily retained molars. On the other hand, a major problem regarding secondarily retained molars is that these cannot be removed orthodontically because of areas of ankylosis in the periodontal ligament (PDL) or obliteration of PDL (16). Severe inclination requires surgical methods or orthodonticallyassisted eruption with or without surgical uncovering. Surgical repositioning with or without extraction of the third molar or extraction of the impacted second molar to allow either eruption of the third molar or transplanting the third molar to the second molar socket may be required $(17,18)$.

However, orthodontic treatment of an impacted tooth is not always possible or practical. In clinical practice, the position and direction of the impacted tooth, the amount of root formation, and the degree of root dilacerations are used to determine whether an impacted tooth can be successfully aligned in a proper position (19). The best time to orthodontically treat impacted mandibular molars is between 10-17 years of age, when development of the second permanent molar roots is still incomplete (20). Extraction of the impacted molar is indicated when surgical exposure and orthodontic treatment cannot lead to eruption, or if a pathologic lesion is present. In our study, the mean age of the patients was 22.69 years when the apexes of the molar tooth were complete. Due to the possible associated complications, surgical removal was indicated in most of the cases 119 (59.5\%) in our study. Orthodontic treatment was planned in 47 cases and the remaining followed up regularly. If neither an early diagnosis nor early treatment is provided, loss of the molar is the most common final result. Therefore, early diagnosis is critical.

Because of the retrospective nature of our study, we did not have access to treatment results of all patients. Many factors such as age, occlusion and position of impacted teeth, pathological conditions, and patients' cooperation should be discussed when making treatment decisions (21). In addition, it is important that clinicians inform patients of the risks and benefits of the proposed 
procedures, particularly surgical complications such as possible damage to the inferior alveolar nerve and mandibular fracture (22).

To our knowledge, there has been no study in the literature that analyzed the number of patients examined in this study. Published reports are mostly based on single case reports, and there is a lack of uniformity in the management of impacted teeth. Even if the impactions of first and second permanent molars do not occur frequently, it is important to make an early diagnosis in order to begin treatment at the optimal time.

\section{References}

References with links to Crossref - DOI

1. Sawicka M, Racka-Pilszak B, Rosnowska-Mazurkiewicz A. Uprighting partially impacted permanent second molars. Angle Orthod. 2007;77:148-54.

2. Valmaseda-Castellón E, De-la-Rosa-Gay C, Gay-Escoda C. Eruption disturbances of the first and second permanent molars: results of treatment in 43 cases. Am J Orthod Dentofacial Orthop. 1999; 116:651-8

3. Mariano RC, Mariano Lde C, de Melo WM. Deep impacted mandibular second molar: a case report. Quintessence Int. 2006;37:773-6.

4. Hicks MJ, Greer RO Jr, Flaitz CM. Delayed eruption of maxillary permanent first and second molars due to an ectopically positioned maxillary third molar. Pediatr Dent. 1985;7:53-6.

5. Raghoebar GM, Boering G, Vissink A, Stegenga B. Eruption disturbances of permanent molars: a review. J Oral Pathol Med. 1991;20:159-66.

6. Jacobs SG. The surgical exposure of teeth--simplest, safest and best? Aust Orthod J. 1987;10:5-11.

7. Brearley LJ, McKibben DH Jr. Ankylosis of primary molar teeth. I. Prevalence and characteristics. ASDC J Dent Child. 1973;40:54-63.

8. Grover PS, Lorton L. The incidence of unerupted permanent teeth and related clinical cases. Oral Surg Oral Med Oral Pathol. 1985;59:420-5.

9. Pytlik W, Alfter G. Impairment of tooth eruption. Pathogenetic aspects. J Orofac Orthop. 1996;57:238-45.

10. Dachi SF, Howell FV. A survey of 3, 874 routine full-month radiographs. II. A study of impacted teeth. Oral Surg Oral Med Oral Pathol. 1961;14:1165-9.

11. Wellfelt B, Varpio M. Disturbed eruption of the permanent lower second molar: treatment and results. ASDC J Dent Child. 1988;55:183-9.

12. Evans R. Incidence of lower second permanent molar impaction. Br J Orthod. 1988;15:199-203.

13. Kemp WB. Impaction of a mandibular first permanent molar. Oral Surg Oral Med Oral Pathol. 1980;49:95.

14. Jacobson A. The physiology of tooth eruption. Birth Defects Orig Artic Ser. 1983;19:67-82.

15. Bondemark L, Tsiopa J. Prevalence of ectopic eruption, impaction, retention and agenesis of the permanent second molar. Angle Orthod. 2007;77:773-8.

16. Raghoebar GM, Boering G, Vissink A, Stegenga B. Eruption disturbances of permanent molars: a review. J Oral Pathol Med. 1991;20:159-66.

17. McAboy CP, Grumet JT, Siegel EB, Iacopino AM. Surgical uprighting and repositioning of severely impacted mandibular second molars. J Am Dent Assoc. 2003;134:1459-62.

18. Fieldhouse J, Shields C. Surgical uprighting of an impacted mandibular second molar. Dent Update. 1997;24:320-2.

19. Tanaka E, Kawazoe A, Nakamura S, Ito G, Hirose N, Tanne Y, et al. An adolescent patient with multiple impacted teeth. Angle Orthod. 2008;78:1110-8.

20. Moro N, Murakami T, Tanaka T, Ohto C. Uprighting of impacted lower third molars using brass ligature wire. Aust Orthod J. 2002; $18: 35-8$
21. Babacan H, Ay S, Köşger HH. Impacted permanent first molars: two case reports. Int Dent J. 2006;56:49-54.

22. Metin M, Sener I, Tek M. Impacted teeth and mandibular fracture. Eur J Dent. 2007;1:18-20. 